\title{
NEUTRON STREAMING IN PLATE CRITICALS
}

\section{by}

D. C. Wade and E. M. Gelbard

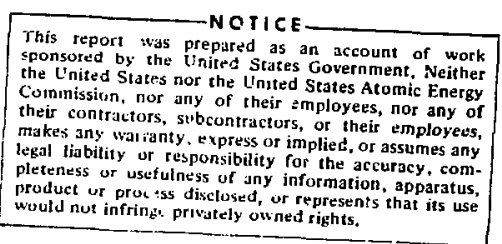

For Presentation at:

American Nuclear Society Topical Meeting on

"Advanced Reactors; Physics, Design and Economics," Atlanta, Georgia, September 8-11, 1974

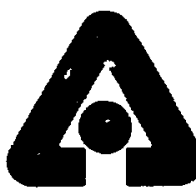

L O O C.AUA USAEC 
Paper for presentation at the American Nuclear Society Topical Meeting on "Advanced Reactors; Physics, Design and Economics," September 8-11, 1974, Atlanta, Georgia.

\section{NEUTRON STREAMING IN PLATE CRITICALS ${ }^{\star}$}

D. C. Wade and E. M. Gelbard Applied Physics Division

Argonne National Laboratory

Argonne, I11inois 60439

\footnotetext{
"Work performed under the auspices of the U. S. Atomic Energy Commission.
} 


\title{
NEUTRON STREAMING IN PLATE CRITICALS
}

D. C. Wade and E. M. Gelbard

Argonne National Laboratory, Argonne, Illinois

\begin{abstract}
Questions concerning neutron streaming in the sodium-void columns of LMFBR and helium-coolant columns of GCFR plate criticals are examined. The homogeneous isotropic diffusion coefficient is shown to substantially underpredict leakage in the axial direction. A misprediction of leakage is shown to produce only slight errors in neutron spectrum and such integral parameters as fission ratio. However, eigenvalue and material worths are found to be quite sensitive to leakage. One-dimensional unit cell modeling prescriptions are described which yield accurate cell-average, microscopic isotopic cross sections and Benoist diffusion coefficients in the presence of streaming.
\end{abstract}

\section{INTRODUCTION}

The plate geometries used in Argonne National Laboratory's fast critical facilities, $Z P R-6, Z P R-9$, and $Z P P R$, possess air-filled neutron streaning paths. Three forms of path are encountered: (1) an air-cooling gap between the tops of the fuel and structure plates and the bottom of the next-higher drawer-amounting to a unit cell volume fraction of a few percent; (2) voided sodium channels (volume fraction approximately 40 vo1-\%) in LMFBR experiments; and (3) simulated helium-coolant channels in GCFR critical experiments (volume fraction approximately 45-55 vol-\%). These streaming paths affect the neutron balance and the values of the integral parameters measured in the facilities. For example, Zolotar et al (1) have found noticeable effects on results of $\mathrm{pin} / \mathrm{plate}$ heterogeneity comparisons.

An effort is under way to understand streaming effects in plate criticals and to develop calculational procedures for treating streaming within a diffusion theory framework. The results reported here pertain to three questions:

(1) What are the effects of errors in leakage on the gross characteristics of the neutron balance in a plate critical?

(2) What are the effects of streaning on the flux fine structure in space and energy within a plate critical (drawer) unit cell? Specifically, what effect does streaming have on the generation of cel1-average, broad-group, microscopic cross sections?

Work performed under the auspices of the U. S. Atomic Energy Commission. 
(3) Can the Benoist formalism be applied to the description of streaming in plate criticals? If so, what modeling prescription is appropriate?

\section{GROSS EFFECTS OF LEAKAGE ON THE NEUTRON BALANCE}

The gross consequences of a calculational misprediction of neutron leakage have been indicated by examination of 27 multigroup, zero-dimensional calculations of a sodium-voided LMFBR unit cell. Two calculations were compared; one for a critical buckling and one in which the group-independent value of buckling was arbitrarily increased by $10 \%$ over its critical value.

Figure 1 shows the single-drawer unit cell and Table I lists its material number densities for a one-dimensional representation. The voided sodium channels constitute a cell volume fraction of 39.1 vol-\%. The infinite multiplication factor $\left(k_{\infty}\right)$ for the cell is 1.24 .

Cell-average 27 (0.5 lethargy interval) broad-group cross sections were generated for the cell using the SDX (2) code. In SDX, account was taken of heterogeneous resonance self-shielding using an equivalence principle. Also, plate self-shielding factors were generated at a 0.1 lethargy interval level using a collision probability technique. A critically buckled spectrum was usea to coalesce to the 27-group set. No anisotropic diffusion was accounted for. The modeling prescription used in SDX is further described in the next section.

For the critically buckled unit cell, Table III shows the flux and adjoint spectra, the leakage, and the total mean-fiee path by energy group.

In order to determine the sensitivity of the neutron balance and associated integral parameters to leakage, the unit cell was recalculated for a group-independent $10 \%$ increase in buckling. This produced an eigenvalue change of $0.9746-1.0000=-0.0254 \Delta \mathrm{k}$.

With $L$ denoting the leakage probability and

$$
k=k_{\infty}(1-L)
$$

for this cel1 $L=1-k / k_{\infty}=0.2$. Then the change in eigenvalue induced by $a$ $10 \%$ increase $i \bar{s}$ leakage probability is:

$$
\frac{\delta k}{k}=\frac{\delta k_{\infty}}{k_{\infty}}-\frac{\delta L}{L} \frac{L}{1-L}=\frac{\delta k_{\infty}}{k_{\infty}}-0.1 \frac{2}{8}=\frac{\delta k_{\infty}}{k_{\infty}}-0.025 .
$$

The agreement with the value of $\Delta k$ determined from calculation shows that any $k_{\infty}$ change induced by a spectral change is quite small.

In agreement with this conclusion, examination of calculated results shows that the increased leakage hardened the flux spectrum only slightly leading to small changes in integral parameters $\left(2 \%\right.$ change in ${ }^{2}(n, f) /{ }^{49}(n, f)$ fission ratio). The adjoint spectrum softened somewhat in response to increased leakage. Table ITI shows the changes in the flux and adjoint. The cumulative effect of energetic neutron leakage depleting the scattering source 
to lower energies is responsible for the flux hardening. The increased leakage probability at high energies makes energetic neutrons less likely to continue the chain reaction-explaining the softening of the adjoint spectrum.

As a result of the balance of competing effects, the slight hardening of the $f 1 u x$ and softening of the adjoint introduced rather large changes in some material worths, particularly those of scatterers. The spectrun shifts introduced by a $10 \%$ increase in buckling produced the increases in algebraic value of worth shown in Table IV for the important cell constituents. The table also shows the additional increase attributable to the increased value of buckling.

The results of these simple calculations lead to several conclasions:

(1) A $10 \%$ misprediction of leakage has a rather sma11 effect on such integral parameters as fission ratios and breeding ratios. Increased leakage slightly hardens the flux and softens the adjoint spectra.

(2) However, because leakage is a $20-30 \%$ component of the neutron balance, the eigenvalue is substantially affected by mispredictions of leakage. Also, material worths-particularly those of scattersare extremely sensitive functions of the flux and adjoint spectra and therefore of leakage.

\section{EFFECTS OF STREAMING ON BROAD-GROUP CROSS-SECTION GENERATION}

The SDX code used to generate cell-average, isotopic, microscopic cross sections is a one-dimensional code. Thus, the physical three-dimensional unit cell must be modeled in one-dimension and, in particular, structural material from the cell edges must be introduced into the one-dimensional representation. The traditional procedure has involved putting the structural material from the drawer ends and matrix tube top and bottom into the nonfissile regions of the one-dimensional cell. In this way the optical thickness of the fuel plates and the resonance absorber to scattering atom ratios within the fuel plates are maintained. However, the optical thickness of the structural regions change. Also, because different plates have different heights, the one-dimensional volume fractions and true three-dimensional volume fractions differ so that the one-dimensional model preserves neither cell-average number density nor ratios of cell-average number densities. ${ }^{*}$ of particular interest in the case of streaming is that structural material from the cell edges is introduced into the void columns.

This modeling procedure raises several questions concerning leakage: Does the error in leakage resulting from (a) not preserving cell-average number densities; and (b) introducing structural material into the void columns significantly affect the values of cell-average, broad-group isotopic microscopic cross sections? To answer this question two Monte Carlo cell calculations were compared: one for a true three-dimensional cell and one for a onedimensional cell modeled according to the above-described prescription. A GCFR unit cell served as the model.

The proper cell-average number densities are restored in two-dimensional diffusion theory calculations which use the microscopic, isotopic cross sections generated in the one-dimensional SDX model. 
Figure 2 shows the GCFR unit cell. The conventions for naming "length", "width", and "height" are shown in the figure. Table II lists the material number densities. The helium-coolant void channels contribute a cell volume fraction of $51.7 \mathrm{vol}-\%$, and the air-cooling void occupies an additional 3.04 vol-q. The infinite multiplication factor of the cell is 1.46 .

Three-dimensional calculations of 54,000 histories were made for the two unit cells using the continuous energy Monte Carlo code, VIM (3). The cells were made $72.5 \mathrm{in}$. long (parallel to the plates) with vacuum boundary conditions to correspond to the proposed GCFR critical experiments. Reflecting and/or periodic conditions were used on the other cell extremities to represent an infinite array of such cells; thus leakage occurred only in the $Z$ (length) direction.

From the edits of plate-wise isotopic microscopic cross sections produced by the two calcualtions it was verified that to within the statistical uncertainty ( $\pm<0.1 \%$ over most of the important energy range) the two unit cells produced identical cross sections. Also, comparison of the two intra-cell flux shapes in different energy bands showed close agreement. This agreement indicates that plate self-shielding factors are not significantly affected by the approximations made in the one-dimensional modeling approach.

Table $V$ displays the fractions of $Z$ leakage going out each of the void and non-void columns at the end of the unit cell. In addition, the area fractions subtended by these columns are shown. The close correlation indicates that the $Z$ leakage is almost uniformally distributed across the end of the cell and is not localized to the void columns. It is noted that the total mean-free path is of the same characteristic length as the drawer width (see Table III).

While the results show that the approximations made in modeling the onedimensional cell do not significantly affect the microscopic isotopic cross sections or the plate self-shielding factors generated by the one-dimensional calculation, the overall neutron balance is significantly affected. Table VI compares the eigenvalues and the isotopic absorption and fission production fractions obtained in the two calculations. It is seen that the eigenvalue increased from 1.24 to 1.30 and the leakage fraction decreased from 0.1585 to 0.1303 in going from the true to the one-dimensional cell representation. These changes can be shown to be attributable strictly to the cell-average number density differences between the true cell and one-dimensional model. Again, using Eqs. (1) and (2) and the facts that:

$$
\begin{aligned}
\mathbf{k}_{\infty} & =\frac{\text { Total Fission Production Rate }}{\text { Total Absorption Rate }} \\
L & =\frac{\text { Leakage Rate }}{\text { Total Absorption Rate + Leakage Rate }}
\end{aligned}
$$

the values in Table VI indicate that the $6 \%$ increase in $k$ is attributable to a $2-1 / 2 \%$ increase in $k_{\infty}$ and a 3-1/2\% increase in nonleakage probability. From Table II it is noted that the ratio of cell average $239 \mathrm{Pu}$ number density to that of ${ }^{23 \theta_{U}}$ and other principle absorbers is greater in the one-dimensional cell by $1-1 / 2$ to $6 \%$ than it is in the true cell. This explains the increase in $k_{\infty}$. Furthermore, from Table $I I$ it is seen that the total atom density in 
the one-dimensional cell exceeds that in the true cell by $10.28 \%$ and for the principle scatterers $(\mathrm{Fe}+\phi)$ the excess is $9.36 \%$. In a neutron balance:

$$
\left(-\frac{1}{3 \Sigma_{t r}} B^{2}+v \Sigma_{f}-\Sigma_{a}\right) \phi=0,
$$

it is seen that a $10 \%$ increase in atam density $(\Sigma \rightarrow 1.1 \Sigma)$

$$
\left(-\left[\frac{1}{1.1}\right]^{2} \frac{\mathrm{B}^{2}}{3 \Sigma_{t r}}+\nu \Sigma_{f}-\Sigma_{a}\right) \phi=0
$$

diminishes the leakage component of the balance by roughly twice the percentage change in the density. Thus in the change from the true to the onedimensional cel1, the $17.8 \%$ decrement in the leakage probability corresponds closely to the approximately $9-10 \%$ increase in the atom density.

Several conclusions can be drawn from the Monte Carlo calculations:

(a) The approximations of higher-average densities and stainless-steel insertion in the void channels employed in modeling a unit cell in one dimension do not significantly affect the values of plate selfshielding factors and broad-group, cell-average, microscopic, isotopic cross sections zenesated by the one-dimensional mode 1 .

(b) Substantial eigenvalue, leakage probabi!ity, and $k_{\infty}$ differences between the true and one-dimensional model do exist but are directly attributable to the differences in atom densities.

\section{EVALUATION OF THE BENOIST FORMALISM FOR STREAMING IN PLATE CRITICALS}

In a plate critical the void slots are interrupted in the length direction only by drawer fronts and backs while in the vertical direction the drawer bottom and matrix tubes constitute interruptions having an optical thickness about ten times larger. Thus, the total mass of structural material "seen" by neutrons depends strongly on their direction of motion.

In the diffusion theory approximation, the value of the diffusion coefficient, $D$, determines the neutron leakage. In the presence of streaming, the homogeneous isotropic D is known to underpredict leakage in directions parallel to void slots. Benoist's method (4) provides a means to correct the situation with anisotropic values for $D$. In view of the different optical thickness seen by neutrons traveling in different directions, it would seem that different smeared densities are appropriate for the generation of Benoist D's in the differerit directions.

It is to be remembered that in slab lattices the Benoist diffusion coefficient for streaning parallel to the plates becomes infinite when any rigion of the lattice cell becomes a true void (4). Clearly the Benoist method is then invalid. Furthermore, the Benoist formulation employs a buckling expansion with second and higher-order terms in $B^{2}$ neglected to facilitate an analytic solution. Corrections to the Benoist $D$ due to higher powers of $B^{2}$ can be obtained by the numerical solution of a transport equation (5) and are shown below to increase in magnitude as the optical thickness of the void slot 
becomes smaller. In view of these facts it is important to carefully test the Benoist method for use oi. plate criticals.

To test the appropriateness of Benoist diffusion coerficients in the presence of streaming, one-dimensional and two-dimensional calculations were made on idealizations of the sodium-voided LMFBR unit cell shown in Fig. 1 and described in Table I. The first set of calculations employed a one-dimensional representation of the wit cell in which the "smeared structure" density in the void slots was successively decreased starting from densities obtained by the one-dimensional modeling procedure described in the preceeding section and ending at densities characteristic of the optical thickness "seen" by a neutron traveling in the length direction down a void slot. Table VII shows the resulting values of diffusion coefficients for several of the energy groups having high leakage: Three diffusion coefficients are shown: (1) the volumeweighted, homogeneous, isotropic value of $D$; (2) the Benoist $D_{2}$; and (3) the Benoist $D_{2}$ corrected for higher-order terms. The Benoist $D$ and the corrections to it were obtained using an $S_{n}$ method. The results shown in Table VII show that: (a) the homogeneous, isotropic $D$ values are substantially too smallapproximately $12 \%$ at nominal density and approximately 14-17\% at low density; and (b) the uncorrected Benoist D is slightly (approximately $2 \%$ ) too large at nominal density and at low density it is substantially too large (approximately $10 \%$ ). It is clear that the homogeneous, isotropic $D$ is unacceptably low and a corrected $D$ is required. However, both the value and the accuracy of the Benoist $D$ depend crucially on the value of total cross section assumed to be smeared into the void slot in a one-dimensional modeling of the unit cell.

Despite the inherently multidimensional nature of the streaming phenomena and the sensitivity to modeling shown above, a one-dimensional procedure for generating Benoist $D^{\prime}$ 's is required in the interest of ease and computer time. Several one-dimensional modeling procedures were considered. To test a postulated procedure, a two-dimensional and a corresponding one-dimensional calculation of the unit ell were compared. In the most successful approach found the two-dimensional and one-dimensional models were constructed as follows:

(a) The structural material along the length of the void colurms in the three-dimensional unit cell was homogenized uniformly into the void columns producing the two-dimensional model.

To generate the equivalent ore-dimensional model:

(b) the top and bottom subassembly walls were removed;

(c) the plates were stretched to fill the space vacated by step (b); and

(d) the material from step (b) was distributed to the nonfuel regions (including the void column) in amounts proportional to the region volume fraction.

As opposed to the modeling procedure described in the previous section, this procedure conserves cell-average number densities and hence cell-average $\Sigma_{\text {tot }}$.
It does not preserve fuel plate optical thickness, however.

It : a shown in Ref. 5 that the Benoist diffusion coefficient can be olving two coupled transport equations. The solution of the first .. simply the angular flux in the cell, unperturbed by leakage. This 
flux appears as a source in the second equation. To simplify the computation it was assumed that the unperturbed flux is flat and isotropic. The second equation was then solved via TWøTRAN using a specially designed ordinate set. This set consists of 544 ordinates (the same number of ordinates as in a conventional S32) arranged on 16 cones. The cosines of the vertex angles of the cones are the roots of a Legendre polynomial, as in Gauss quadrature. Ordinates are uniformly spaced and uniformly weighted in each cone, with the net weight in each cone set equal to the corresponding Gauss quadrature weight. The top eight cones (those closest to the $Z$ axis) contained 36 ordinates each, while the others each contained 32 ordinates. This arrangement is designed to crowd ordinates in the near-vertical directions, since these directions are important in streaning calculations.

The resulting values of Benoist $D_{z}$ for the two-dimensional and onedimensional calculations are shown in Table VIII for energy groups 6 and 9. Because of the conservation of $\Sigma_{\text {tot }}$, the two-dimensional and one-dimensional cells produce identical values for the volume-weighted, homogeneous, isotropic $D$ which is also shown in the table.

The results in Table VIII show that in agreement with the one-dimensional study the value of homogeneous isotropic $D$ is substantially low. Also, the Benoist D obtained in the one-dimensional calculation is in close agreement with the value fron the more realistic two-dimensional modeling.

The results indicate that the "effective" $\Sigma_{\text {tot }}$ to put into the void slot in the one-dimensional modeling of $z$ direction neutron streaming is not the density corresponding to the optical thickness in the $z$ direction but rather is obtained by the same modeling procedure used to generate cell-average cross sections-with one change. The cell-average number densities are to be preserved.

Higher-order buckling corrections to the Benoist D are difficult to compute in two dimensions and were not obtained. However, it is reasonable to assume that the corrections shown in Table VII for the nominal void column density apply to the two-dimensional and one-dimensional values in Table VIII. The correction is of the order of only $2 \%$. Using the assumption it is found that the isotropic homogeneous $D$ for the cell is too 10 by $5.0 \%$ and $10.9 \%$ in groups 6 and 9 respectively.

The results of these studies indicate that:

(a) the leakage parallel to void slots in substantially underpredicted if a homogeneous, isotropic D is used;

(b) the one-dimensional modeling procedure described above (which preserves $\left.\Sigma_{\text {tot }}\right)$, is adequate for the generation of Benoist D's; and

(c) the higher-order buckling corrections to the Benoist D are small for the cases of interest in plate criticals.

\section{CONCLUSIONS}

The studies completed to date have shown that a homogeneous, isotopic diffusion coefficient substantially underpredicts leakage in plate criticals with streaming paths, and that an underprediction of leakage will have an important 
effect on eigenvalue and material worths. One-dimensional modeling procedures have been shown to produce correct broad-group, microscopic, isotropic cross sections and Benoist diffusion coefficients.

Further questions remain. What about streaming in the $y$ direction? What is the effect of using the Benoist method in regions where there is no wel1defined buckling, as near zone interfaces? Stould the Benoist $D$ be generated on a broad-group basis or on a fine-group basis with subsequent coalescing to a broad-group value? These questions are currently being studied.

\section{ACKNOWLEDGMENT}

The Monte Carlo calculations were conducted by Miss Kathleen A. Denetri .

\section{REFERENCES}

1. B. A. ZOLOTAR, G. GRASSESCHI and P. H. KIER, "Analysis of Plate-Rod Heterogeneity Measurements in Demonstration Reactor Benchmark Assemblies Including the Effect of Streaming," Trans. Am. Nucl. Soc., 18, 309 (1974).

2. W. M. STACEY, ET AL, "Studies of Methods for Fast Neutron Multigroup Cross Section Generation and Their Effect Upon the Neutronics Properties of LMFBR Critical Assemblies," in Proc. Conference on New developments in Reactor Physics and Shielding, USEAC CONF-720901, Book 1 (1972), p. 211.

3. L. B. LEVITT and R. C. LEWIS, "VIM-1," Atomics International Report AI -AEC-1 2951 (1970) .

4. P. BENOIST, "Theorie du Coefficient de Diffusion des Neutrons Dans un Reseau Comportant des Cavites," CEN-Saclay Report CEA-R2278 (1964).

5. E. M. GELBARD, "Anisotropic Neutron Diffusion in Lattices of the Zero Power Plutonium Reactor Experiments," Nucl. Sci. Eng., 54, 327 (1974).

TABLE I. Sodiun-Voided LMFBR One-Dimensional Ce11 Number Densitíes $\times 10^{-24}$

\begin{tabular}{|c|c|c|c|c|c|c|c|}
\hline Isotope & $\begin{array}{l}\text { Cell } \\
\text { Sides }\end{array}$ & $\begin{array}{c}\mathrm{U}_{3} \mathrm{O}_{8} \\
\text { Plates }\end{array}$ & $\begin{array}{l}\text { Void } \\
\text { Clad }\end{array}$ & $\begin{array}{c}\text { Void } \\
\text { Columns } \\
\end{array}$ & $\begin{array}{r}\mathrm{Fe}_{2} \mathrm{O}_{3} \\
\text { Plates } \\
\end{array}$ & $\begin{array}{l}\text { Fuel } \\
\text { Clad }\end{array}$ & $\begin{array}{c}\mathrm{Pu} / \mathrm{U} / \mathrm{Mo} \\
\text { Fuel } \\
\end{array}$ \\
\hline $\begin{array}{l}2{ }^{39} \mathrm{Pu} \\
240 \mathrm{Pu} \\
241 \mathrm{Pu} \\
242 \mathrm{Pu} \\
241 \mathrm{Am} \\
235_{\mathrm{U}} \\
238_{\mathrm{U}}\end{array}$ & & $\begin{array}{l}0.336-4 \\
0.157-1\end{array}$ & & & & & $\begin{array}{l}0.108-1 \\
0.143-2 \\
0.161-3 \\
0.173-4 \\
0.351-4 \\
0.673-4 \\
0.301-1\end{array}$ \\
\hline $\begin{array}{l}\mathrm{Fe} \\
0 \\
\mathrm{Cr} \\
\mathrm{Ni} \\
\mathrm{Mo} \\
\mathrm{M} / \mathrm{n}\end{array}$ & $\begin{array}{l}0.447-1 \\
0.250-3 \\
0.126-1 \\
0.548-2 \\
0.500-4 \\
0.101-2\end{array}$ & $0.420-1$ & $\begin{array}{l}0.683-1 \\
0.380-3 \\
0.194-1 \\
0.983-2 \\
0.750-4 \\
0.147-2\end{array}$ & $\begin{array}{l}0.566-2 \\
0.330-4 \\
0.159-2 \\
0.709-3 \\
0.620-5 \\
0.124-3\end{array}$ & $\begin{array}{l}0.435-1 \\
0.568-1 \\
0.159-2 \\
0.709-3 \\
0.620-5 \\
0.124-3\end{array}$ & $\begin{array}{l}0.571-1 \\
0.320-3 \\
0.164-1 \\
0.812-2 \\
0.630-4 \\
0.141-2\end{array}$ & $\begin{array}{l}0.430-4 \\
0.505-3\end{array}$ \\
\hline
\end{tabular}


TABLE II. GCFR Ce11 Number Densities $\times 10^{-24}$

\begin{tabular}{|c|c|c|c|c|c|c|c|c|}
\hline \multirow[b]{2}{*}{ Isotope } & \multicolumn{8}{|c|}{ One-Dimensional Cel1 by Region } \\
\hline & $\begin{array}{l}\text { Ce11 } \\
\text { Sides }\end{array}$ & $\begin{array}{c}\mathrm{U}_{3} \mathrm{O}_{8} \\
\text { Plates } \\
\end{array}$ & \multicolumn{2}{|c|}{$\begin{array}{l}\text { Void } \\
\text { Clad }\end{array}$} & $\begin{array}{l}\text { Void } \\
\text { Columns }\end{array}$ & $\begin{array}{r}\mathrm{Fe}_{2} \mathrm{O}_{3} \\
\text { Plates } \\
\end{array}$ & $\begin{array}{l}\text { Fue1 } \\
\text { Clad }\end{array}$ & $\begin{array}{l}\mathrm{Pu} / \mathrm{U} / \mathrm{Mo} \\
\text { Fue1 }\end{array}$ \\
\hline $\begin{array}{l}239 \mathrm{Pu} \\
240 \mathrm{Pu} \\
241 \mathrm{Pu} \\
235 \mathrm{U} \\
238 \mathrm{U} \\
\mathrm{Fe} \\
0 \\
\mathrm{Cr} \\
\mathrm{Ni} \\
\mathrm{Mo} \\
\mathrm{Mn}\end{array}$ & $\begin{array}{l}0.442-1 \\
0.189-2 \\
0.123-1 \\
0.538-2 \\
0.998-3\end{array}$ & $\begin{array}{l}0.359-4 \\
0.168-1 \\
0.449-1\end{array}$ & \multicolumn{2}{|c|}{$\begin{array}{l}0.613-1 \\
0.219-2 \\
0.176-1 \\
0.889-2 \\
0.137-2\end{array}$} & $\begin{array}{l}0.466-2 \\
0.199-3 \\
0.131-2 \\
0.586-3 \\
0.104-3\end{array}$ & $\begin{array}{l}0.416-1 \\
0.556-1 \\
0.131-2 \\
0.586-3 \\
0.104-3\end{array}$ & $\begin{array}{l}0.543-1 \\
0.199-3 \\
0.156-1 \\
0.771-2 \\
0.133-2\end{array}$ & $\begin{array}{l}0.111-1 \\
0.150-2 \\
0.156-3 \\
0.707-4 \\
0.316-1 \\
0.100-3 \\
0.150-3 \\
0.285-2\end{array}$ \\
\hline \multirow{2}{*}{ Mn } & \multicolumn{3}{|c|}{$\begin{array}{l}\text { Ce11 Average } \\
\text { No. Densities } \times 10^{-24}\end{array}$} & \multirow{2}{*}{\multicolumn{2}{|c|}{$\begin{array}{l}\text { Ratio } \\
\text { 1-D/True }\end{array}$}} & & & \\
\hline & True Cell & I-D Cel & & & & & & \\
\hline $\begin{array}{l}2{ }^{39} \mathrm{Pu} \\
240 \mathrm{Pu} \\
241 \mathrm{Pu} \\
235 \mathrm{U} \\
238 \mathrm{U} \\
\mathrm{Fe} \\
\mathrm{O} \\
\mathrm{Cr} \\
\mathrm{Ni} \\
\mathrm{Mo} \\
\mathrm{Mn}\end{array}$ & $\begin{array}{l}0.888-3 \\
0.120-3 \\
0.124-4 \\
0.915-5 \\
0.417-2 \\
0.141-1 \\
0.106-1 \\
0.286-2 \\
0.126-2 \\
0.227-3 \\
0.223-3\end{array}$ & $\begin{array}{l}0.103-2 \\
0.138-3 \\
0.144-4 \\
0.104-4 \\
0.474-2 \\
0.153-1 \\
0.117-1 \\
0.311-2 \\
0.144-2 \\
0.263-3 \\
0.250-3\end{array}$ & & $\begin{array}{l}1.1 \\
1.1 \\
1.1 \\
1.1 \\
1.1 \\
1.0 \\
1.1 \\
1.0 \\
1.1 \\
1.1 \\
1.1\end{array}$ & & & & \\
\hline
\end{tabular}

TABLE IV. Sodium-Void Unit Cell Dependence of Material Worth on Leakage

\begin{tabular}{l|c|c|r}
\hline \multirow{4}{*}{ Isotope } & \multicolumn{3}{|c}{ \& Increase in Worth } \\
\cline { 2 - 4 } & $\begin{array}{c}\text { Due to 10\% Increase in } B^{2} \\
\text { Shift }\end{array}$ & $\begin{array}{c}\text { Increased } \\
B^{2}\end{array}$ & Total \\
\hline $239 \mathrm{Pu}$ & 3.35 & 0.22 & 3.57 \\
$238_{\mathrm{U}}$ & 4.99 & 7.08 & 12.07 \\
$\mathrm{Na}$ & 6.98 & 24.16 & 31.14 \\
$16_{0}$ & 25.61 & 58.74 & 84.35 \\
$\mathrm{Fe}$ & 6.90 & 84.32 & 91.22 \\
\hline
\end{tabular}


TABLE III. Flux, Adjoint, Leakage, and Mean Free Path Versus Energy for Sodium-Voided LMFBR Unit Celi

\begin{tabular}{|c|c|c|c|c|c|c|c|c|}
\hline \multirow[b]{2}{*}{ Group } & \multirow[b]{2}{*}{ Energy } & \multicolumn{5}{|c|}{ Critically Buckled } & \multicolumn{2}{|c|}{$\begin{array}{l}10 \% \text { Increase } \\
\text { in Buckling }\end{array}$} \\
\hline & & $\begin{array}{l}\text { Flux } \\
(\xi)\end{array}$ & $\begin{array}{c}\text { Adjoint } \\
(\%)\end{array}$ & $\begin{array}{c}\text { Leakage } \\
(\%)\end{array}$ & $\begin{array}{c}\text { Accumulated } \\
\text { Leakage } \\
\left(\frac{\%}{6}\right)\end{array}$ & $\begin{array}{c}\text { Total Mean } \\
\text { Free Path } \\
(\mathrm{cm})\end{array}$ & $\begin{array}{c}\text { Flux } \\
\text { Change } \\
(\%)\end{array}$ & $\begin{array}{c}\text { Adjoint } \\
\text { Change } \\
\left(\frac{8}{6}\right)\end{array}$ \\
\hline $\begin{array}{l}1 \\
2 \\
3 \\
4 \\
5\end{array}$ & $\begin{array}{c}\mathrm{MeV} \\
10 . \\
6.06 \\
3.68 \\
2.23 \\
1.35 \\
\mathrm{keV}\end{array}$ & $\begin{array}{l}0.31 \\
1.24 \\
2.99 \\
4.17 \\
5.29\end{array}$ & $\begin{array}{l}5.214 \\
4.432 \\
4.428 \\
4.083 \\
3.621\end{array}$ & $\begin{array}{l}0.67 \\
2.35 \\
5.49 \\
6.93 \\
7.21\end{array}$ & $\begin{array}{r}0.67 \\
3.02 \\
8.50 \\
15.44 \\
22.65\end{array}$ & $\begin{array}{r}13.26 \\
11.52 \\
11.16 \\
10.11 \\
8.28\end{array}$ & $\begin{array}{r}+2.27 \\
+2.26 \\
+2.04 \\
+1.97 \\
+1.79\end{array}$ & $\begin{array}{l}-1.00 \\
-1.24 \\
-1.24 \\
-1.37 \\
-1.60\end{array}$ \\
\hline 6 & $8 2 \longdiv { 1 . }$ & 11.73 & 3.526 & 16.51 & 39.16 & 8.55 & +1.01 & -1.73 \\
\hline 7 & 498. & 9.39 & 3.423 & 9.54 & 48.69 & 6.18 & +0.86 & -1.23 \\
\hline 8 & 302 . & 12.12 & 3.306 & 11.70 & 60.39 & 5.88 & +0.46 & -1.03 \\
\hline 9 & 183. & 12.05 & 3.193 & 11.41 & 71.80 & 5.76 & -0.02 & -0.81 \\
\hline 10 & 111. & 10.01 & 3.068 & 8.00 & 79.80 & 4.86 & -0.44 & -0.49 \\
\hline 11 & 67.4 & 8.51 & 2.919 & 6.36 & 86.17 & 4.56 & -0.87 & -0.27 \\
\hline 12 & 40.9 & 5.95 & 2.797 & 3.74 & 89.90 & 3.81 & -1.16 & -0.07 \\
\hline 13 & 24.8 & 5.80 & 2.743 & 4.61 & 94.51 & 4.83 & -1.49 & 0.00 \\
\hline 14 & 15.0 & 3.94 & 2.760 & 2.49 & 97.00 & 3.84 & -2.00 & +0.29 \\
\hline 15 & 9.12 & 2.00 & 2.822 & 0.83 & 97.83 & 2.52 & -2.20 & +0.40 \\
\hline 16 & 5.53 & 1.78 & 2.920 & 0.83 & 98.66 & 2.84 & -2.42 & +0.51 \\
\hline 17 & 3.35 & 1.13 & 3.057 & 0.44 & 99.10 & 2.38 & -2.56 & +0.62 \\
\hline 18 & 2.03 & 0.80 & 3.229 & 0.49 & 99.58 & 3.75 & -2.89 & +0.62 \\
\hline 19 & $\begin{array}{l}1.23 \\
\mathrm{eV}\end{array}$ & 0.41 & 3.392 & 0.22 & 99.81 & 3.30 & -3.16 & +0.77 \\
\hline 20 & 749 & 0.22 & 3.956 & 0.12 & 99.93 & 3.15 & -3.60 & +0.86 \\
\hline 21 & 454 . & 0.09 & 4.183 & 0.04 & 99.97 & 2.64 & -4.40 & +0.91 \\
\hline 22 & 275 & 0.07 & 4.582 & $\ldots$ & -..- & 2.95 & -3.03 & +0.98 \\
\hline 23 & 101 & 0.01 & 6.245 & $\ldots$ & $\ldots$ & 3.00 & -12.50 & +1.06 \\
\hline 24 & 37.3 & $\cdots$ & 2.539 & $\cdots$ & $\ldots$ & 5.93 & $-\cdots$ & +1.01 \\
\hline 25 & 13.7 & $\cdots$ & 5.152 & $\cdots$ & $\cdots$ & 2.72 & $\cdots$ & +1.09 \\
\hline 26 & 5.04 & --- & 3.011 & $\cdots$ & $-\cdots$ & 3.15 & $\cdots-$ & +1.00 \\
\hline 27 & 1.86 & --- & 5.401 & $\cdots$ & $\cdots$ & 2.19 & $\cdots$ & +1.20 \\
\hline
\end{tabular}


TABLE V. Axial Leakage Fraction Versus Area Fraction

\begin{tabular}{|c|c|c|c|c|}
\hline & \multicolumn{2}{|c|}{ Cell } & \multicolumn{2}{|c|}{ 1-D Ce11 } \\
\hline & $\begin{array}{l}\text { Leakage } \\
\text { Fraction } \\
\quad(\%)\end{array}$ & $\begin{array}{l}\text { Area } \\
\text { Fraction } \\
(\delta)\end{array}$ & $\begin{array}{l}\text { Leakage } \\
\text { Fraction } \\
\quad(\%)\end{array}$ & $\begin{array}{l}\text { Area } \\
\text { Fraction } \\
\quad\left(\frac{a}{a}\right)\end{array}$ \\
\hline $\begin{array}{l}\text { Left Vojd Column } \\
\text { Right Two Void Columns } \\
\text { Horizontal Air Cooling Gap } \\
\text { Rest of Cell }\end{array}$ & $\begin{aligned} & 21.19 \pm 2.4 \% \\
& 31.85 \pm 2.2 \% \\
& 2.82 \pm 6.8 \% \\
& 44.13 \pm 2.0 \%\end{aligned}$ & $\begin{array}{r}20.74 \\
30.95 \\
3.04 \\
45.36\end{array}$ & $\begin{array}{l}22.41 \\
34.52 \\
--\overline{43.05}\end{array}$ & $\begin{array}{l}21.23 \\
32.35 \\
46.42\end{array}$ \\
\hline
\end{tabular}

TABLE VI. CeIl Neutron Balances

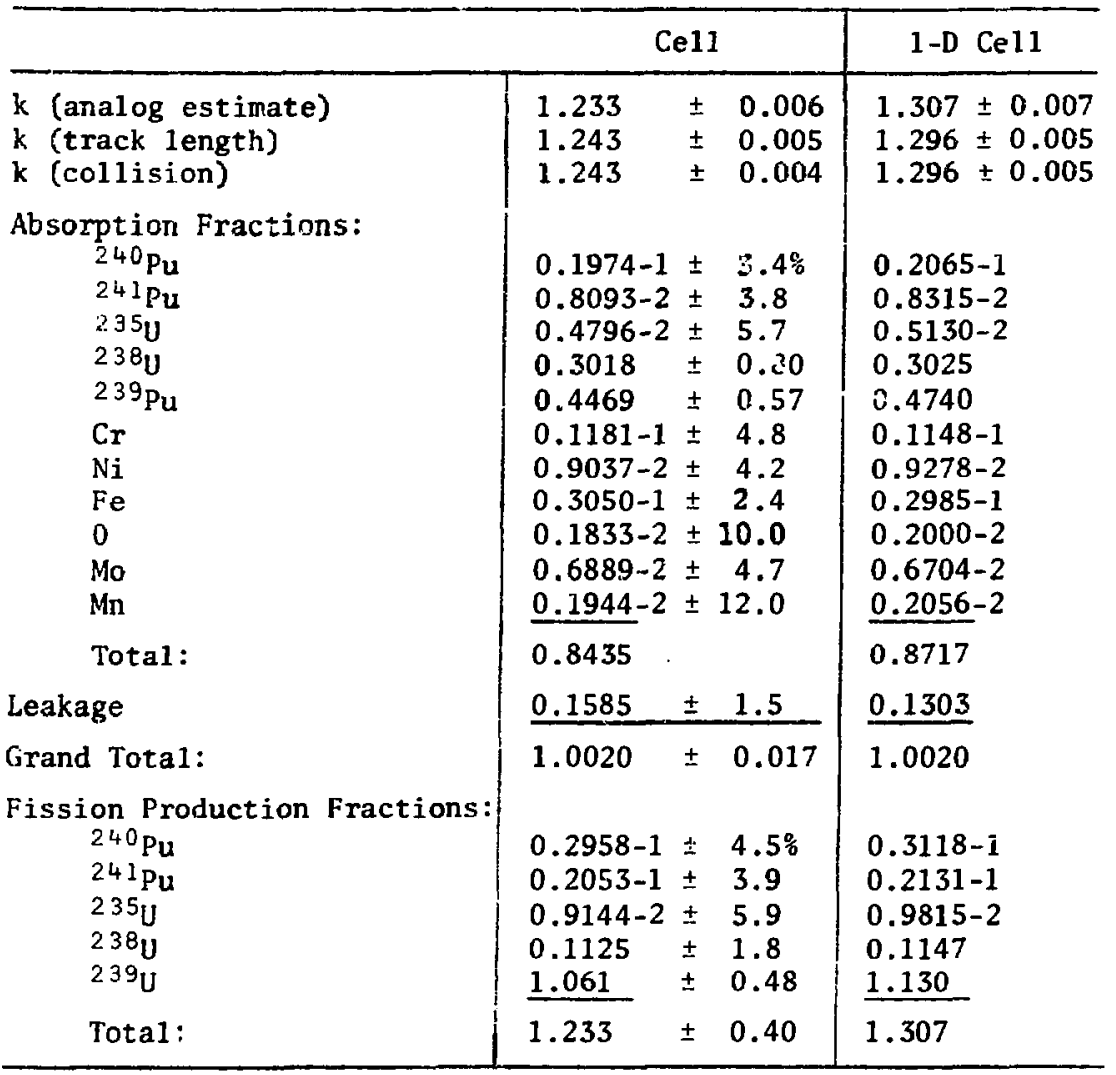


TABLE VII. Sodium-Void Unit Cell $\left(B^{2}=0.000576\right)$. Cell-Average Diffusion Constant Versus "Smeared" Iron Concentration in Void Channel.

\begin{tabular}{l|c|c|c|c}
\hline & $\begin{array}{c}\text { Density } \\
\text { of "Smeared" } \\
\text { Fe in Na- } \\
\text { Void Channe1 } \\
\text { Energy Group }\end{array}$ & $\begin{array}{c}\text { } \\
\text { Anisotropic } \\
\text { D Corrected } \\
\text { for Higher- } \\
\text { Order Terms }\end{array}$ & \multicolumn{2}{|c}{ \& Error in D } \\
\cline { 2 - 5 } Group 1 & 0.5248 & 4.079 & -1.2 & +2.8 \\
6.065-10.0 MeV & 0.2624 & 4.277 & -1.5 & +3.5 \\
& 0.1312 & 4.382 & -1.7 & +4.0 \\
Group 6 & 0.0656 & 4.435 & -1.7 & +4.4 \\
$497.9-820.9 \mathrm{keV}$ & 0.5248 & 2.751 & -6.5 & +2.6 \\
& 0.2624 & 2.864 & -7.3 & +4.5 \\
Group 9 & 0.1312 & 2.928 & -7.6 & +7.1 \\
$111.1-183.2 \mathrm{keV}$ & 0.0656 & 2.951 & -7.7 & +8.8 \\
& 0.5248 & 1.964 & -11.0 & +2.0 \\
Group 11 & 0.2624 & 2.008 & -12.9 & +4.5 \\
$40.9-67.4 \mathrm{keV}$ & 0.1312 & 2.117 & -13.6 & +7.8 \\
& 0.0656 & 2.135 & -13.6 & +10.7 \\
& 0.5248 & 1.598 & -12.8 & +1.2 \\
& 0.2624 & 1.704 & -15.2 & +3.8 \\
& 0.1312 & 1.775 & -17.1 & +6.5 \\
& 0.0656 & 1.800 & -17.5 & +10.1 \\
\hline
\end{tabular}

abtained from cell, volume-weighted $\Sigma_{t r}$.

TABLE VIII. Comparison of Benoist D's from Two-Dimensional and One-Dimensional Mudels

\begin{tabular}{l|c|c|c|c|c|c|c}
\hline & \multicolumn{2}{|c|}{ 2-D Model } & \multicolumn{3}{c|}{1 -D Model } & \multicolumn{2}{c}{ Homogeneous } \\
\cline { 2 - 7 } & $\begin{array}{c}\Sigma_{\text {tot in }} \\
\text { Void Slot }\end{array}$ & $\begin{array}{c}\text { Benoist } \\
\text { Dnergy Group }\end{array}$ & $\begin{array}{c}\sum_{\text {tot }} \text { in } \\
\text { Void Slot }\end{array}$ & $\begin{array}{c}\text { Benoist } \\
\text { D }\end{array}$ & $\begin{array}{c}\% \\
\text { Error }\end{array}$ & D & $\begin{array}{c}\% \\
\text { Error }\end{array}$ \\
\hline $\begin{array}{l}\text { Group } 6 \\
497.9-820.9 \mathrm{keV}\end{array}$ & 0.0013981 & 2.929 & 0.0188900 & 2.884 & -1.54 & 2.710 & -7.48 \\
$\begin{array}{l}\text { Group 9 } \\
111.1-183.2 \mathrm{keV}\end{array}$ & 0.0019224 & 2.085 & 0.025960 & 2.032 & -2.54 & 1.821 & -12.66 \\
\hline
\end{tabular}




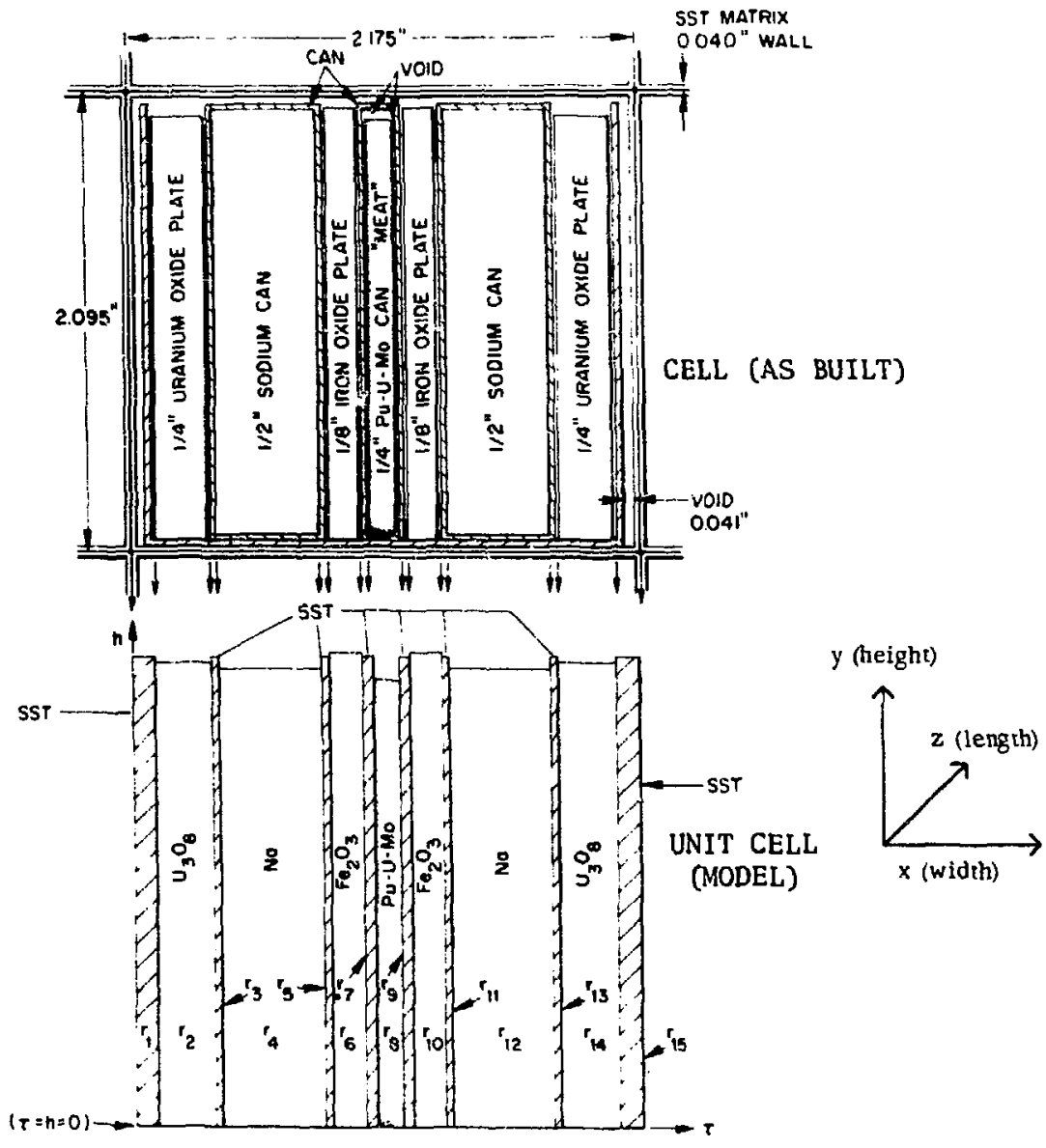

Fig. 1. LMFBR unit cell (dimensions in inches).

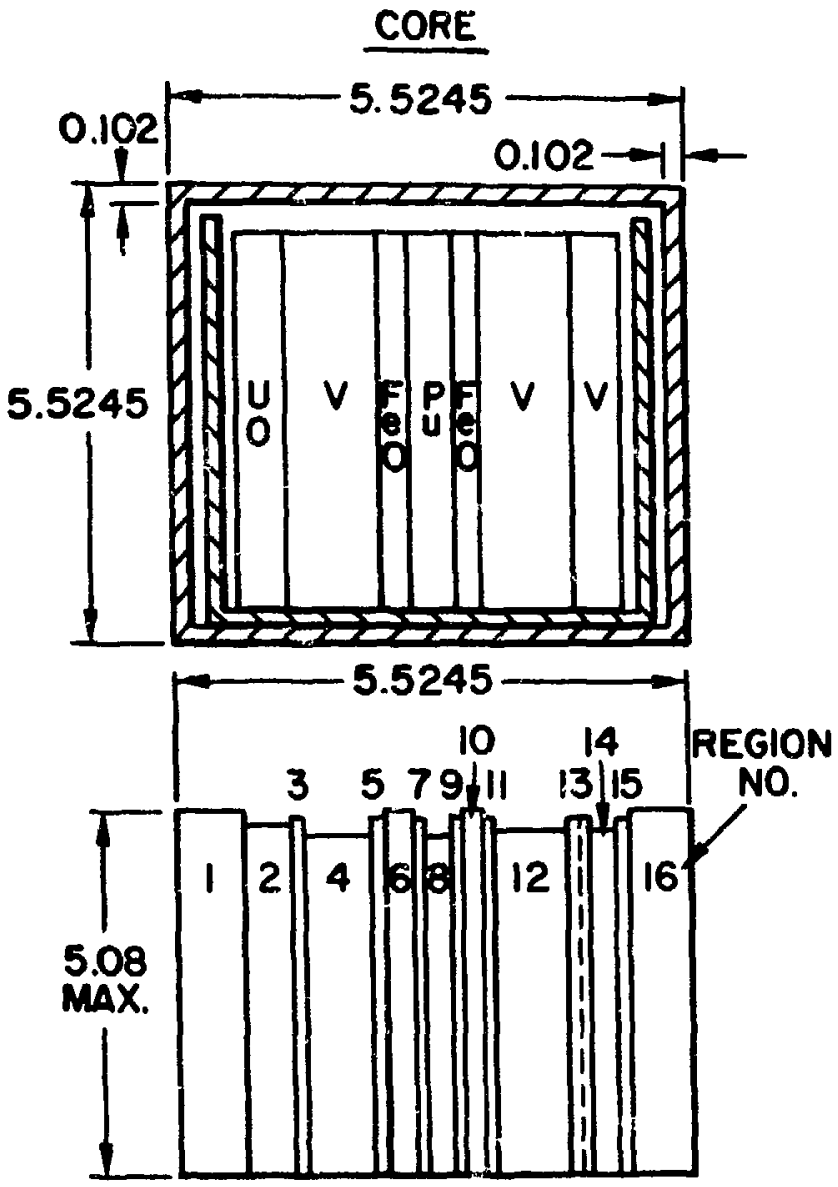

Fig. 2. GCFR unit cell (dimensions in $\mathrm{cm}$ ). 